Journal of Engineering and Applied Sciences 14 (Special Issue 8): 10389-10397, 2019

ISSN: 1816-949X

(C) Medwell Journals, 2019

\title{
The Geotechnical Maps for Physical and Engineering Properties by using GIS Foral-Hillacity
}

\author{
Sajjad Abdulraheem, Zuhair Alasadi and Amer Atyah Alhkalidy \\ Department of Applied Geology, Science College, Babylon University, Babil, Iraq
}

\begin{abstract}
The purpose of this study is to produce geotechnical maps as a tool for collecting, physical and engineering data on the soil of the city of Hilla (residential areas) by using Geographical Information System (GIS). The information is composed of field and laboratory tests and the importance of geotechnical maps used to give an idea of geotechnical properties of studying. In this study, 77 geotechnical maps were prepared for different depths reach to $10.5 \mathrm{~m}$. These maps were prepared based on the reports of the National Center for ConstructionLaboratories (NCCl) as well AL-Mawal Company for Soil Investigation which included the period between (2006-2017) where the maps were based on the results of (115) test bore hole. Geotechnical maps show that the physical properties is percentage of Plastic Limit (PL) is between 7.10-41\% and the Liquid Limit (LL) is between (11-64\%). The wet density varied between $2.04-1.60 \mathrm{gcm}^{-3}$ and the dry density between $1.13-2.30 \mathrm{gcm}^{-3}$ while moisture content ranged values $4.10-31.8 \%$ ). Also the geotechnical maps show that the engineering properties: the maximum soil bearing capacity reached in depth $(4 \mathrm{~m})$ at hole within location in street 60 and the values of Standard Penetration Test (SPT) (2-57 blows) while the cohesive value is between $0.25-5.77 \mathrm{Tm}^{-2}$, friction angle value $\left(0-43^{\circ}\right)$. These values are randomly distributed at different depths on the soil of the city of Hilla.
\end{abstract}

Key words: Engineering properties, physical properties, geotechnical maps, friction, distributed, penetration

\section{INTRODUCTION}

Establishing any engineering development whether this facility (building, bridge, highway, tunnel, dam, etc.) requires time and cost to investigate the soil. Geotechnical maps are needed to decrease expenses and shorten the time. Geotechnical maps are a instrument used to define the soil of any region being studied, these maps being protected in various ways and various programs. GIS program (Geographic Information System) will be used in this study because it is appropriate to the search requirement (Al-Abody, 2016).

Over the years, Geographic Information Systems (GIS) have evolved as a very significant instrument for geospatial data graphic representation. Geotechnical, geological and hydrological information as depicted on GIS maps have had a major effect on civil engineering, particularly in terms of how underground geospatial data is communicated to customers and individuals at wide. Over the past four centuries, GIS has developed as the main technical communication medium as information represented in GIS formats can be disseminated extensively and easily through the use of the World Wide Web. GIS program (Geographic Information System) will be used in this study because it is appropriate to the search requirement (Al-Baaj, 2017).

GIS is a strong instrument in performing such analyzes on very big fields in very short time by assessing enormous amounts of information for geoenvironmental assessment. A key characteristic of a GIS is the capacity to produce fresh information by incorporating current various datasets with a compatible spatial referencing system (Orhan and Tosun, 2010).

The aim of the study is to build geotechnical maps for the collection of geochemical, physical and chemical data for the city of Hilla which includes the following information:

- Bearing capacity and standard penetration test

- Plastic limit, liquid limit, moisture content

- Anglefriction and cohesion value

- Wet density $(\gamma \mathrm{w})$ and dry density $(\gamma \mathrm{d})$

Study area: The study area is located in the city of Hilla (center of the province of Babylon) in the center of Iraq within the plain sedimentary which is located about $100 \mathrm{~km}$ South of the capital Baghdad, a flat area does not exceed the height of $28 \mathrm{~m}$ from the equal surface of the sea and an area of $878 \mathrm{~km}^{2}$. It is enclosed between

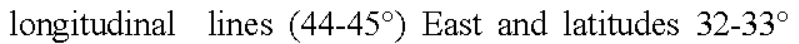
North with grading system and longitude (520000 -40.000 $\mathrm{m}$ ) and latitude ( $3660000-3560000 \mathrm{~m}$ ) by UTM system Fig. 1.

Brief steady region geological history: The Hilla City in Babylon governorate is basic component of the flood

Corresponding Author: Sajjad Abdulraheem, Department of Applied Geology, Science College, Babylon University, Babil, Iraq 10389 


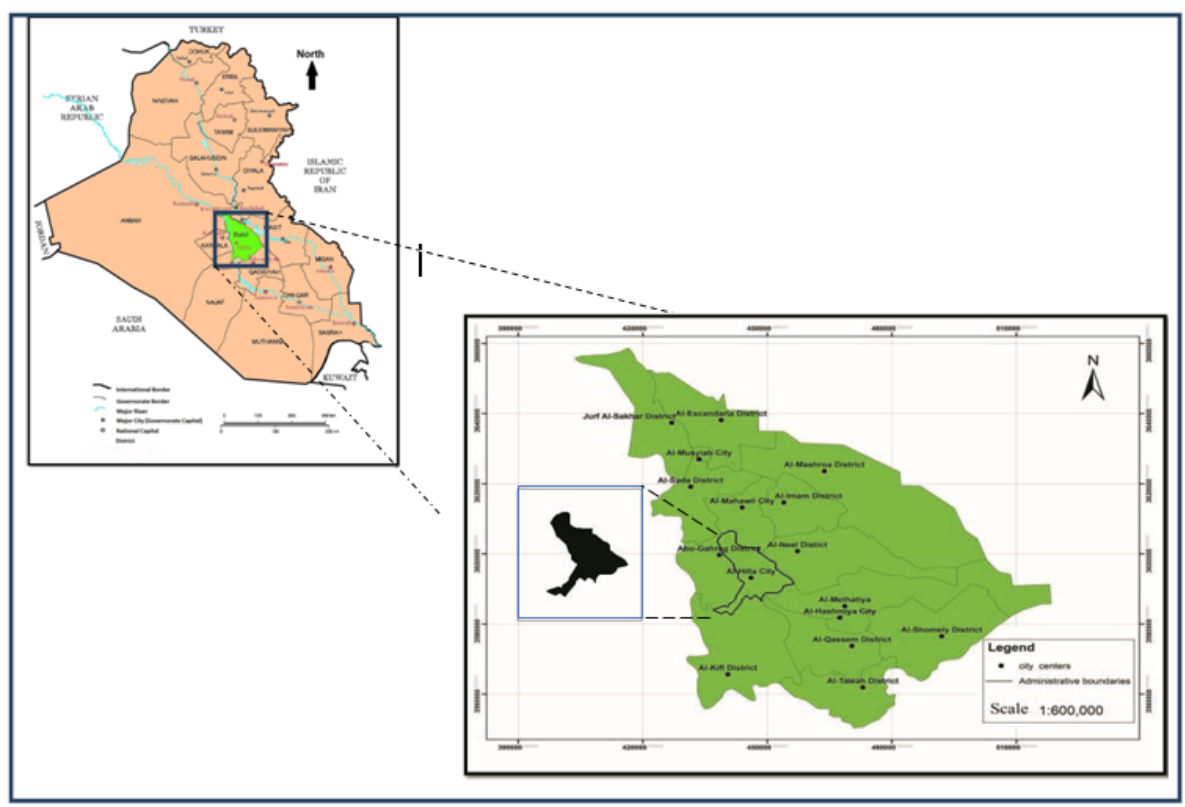

Fig. 1: Location of study area

plain region representing the latest ground development of the geology of Iraq as it includes the resent alluvial sedimentation deposit of the two rivers, Tigers and Euphrates.

The site, however is free from ancient rock surface erosion. The formation of this flood plain belongs to the era of Pleistocene. On the other side, depression fill deposits accumulate as a result of successive floods. Primary soft layers of fine sand and silt, clay and silty clay are formed.

\section{MATERIALS AND METHDOS}

Information gathering stage: Reports from the National Center for Construction Laboratories (NCCL) and AL-Mawal Company for soil investigation took the information used in this study. Data gathered for (115) test boreholes are randomly spread in the residential region of AL-Hilla city this test boreholes have depths of up to $10.5 \mathrm{~m}$.

Field work stage: Located the location by using Global Positioning System (GPS).

The office work stage: Enter data into (ArcGIS10.4.1), and then analyze and process this data to produce geotechnical maps.

\section{Geotechnical properties}

Physical soil properties

Description of soil layers: According to the information gathered, Al-Hilla city's soil is a layered soil, these layers are: silty sand, clayey sand, sand distributed randomly to the depths as shown in Fig. 2ab showing some boreholes samples in Al-Hilla city, the other boreholes are roughly comparable to those boreholes.

Wet density and dry density: The weight unit provides a good estimate or data on soil circumstances in terms of overload stress as well as the over-consolidation ratio determination. Settling and calculating the holding structure's lateral earth stress. The friction angle in the cohesive soil counts on the weight unit (Jumikis, 1962).

Calculated wet density varied between $1.60-2.04 \mathrm{gcm}^{-3}$ for al-Hilla soil. While dry density varied between 1.13-2.30 $\mathrm{gcm}^{-3}$. Geotechnical maps for the soil layer under foundation for depths $(0-10.5 \mathrm{~m})$ were prepared. Figure 3 and 4 shows wet density and dry density for soil Hilla city in depth $(1.5 \mathrm{~m})$.

Moisture Content MC: Moisture content plays an significant role in the calculation of structural soil analysis, particularly in soil-related elevated gypsum content. Due to the moisture content information acquired at depths $(0-10.5 \mathrm{~m})$ above ground level, the results accessible for 115 test boreholes, spatial analysis procedure for this. The test according to standard (ASTM D-2216-05).

Where moisture content values in Al-Hilla city ranged between $4.10-31.8 \%$ as shown in Fig. 5 for predictive maps of moisture content at different depths.

Standard Penetration Test (SPT): Standard Penetration Tests (SPT) were done at periodic intervals in accordance 
(a)

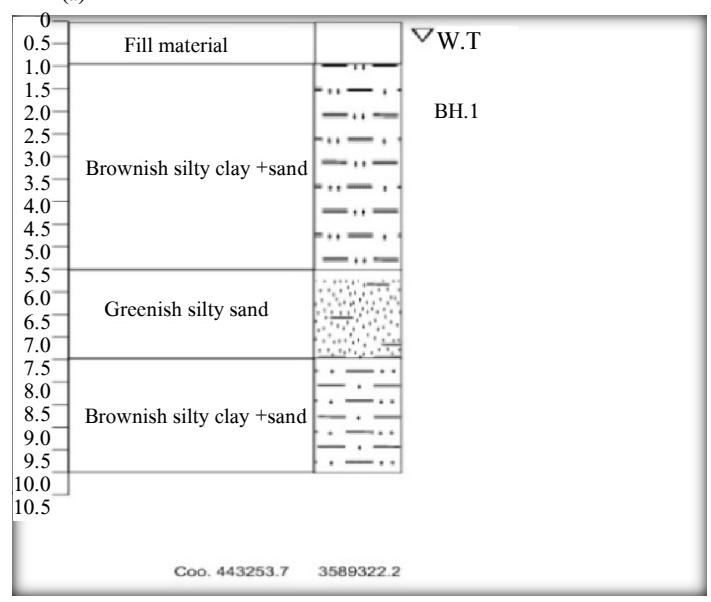

(b)

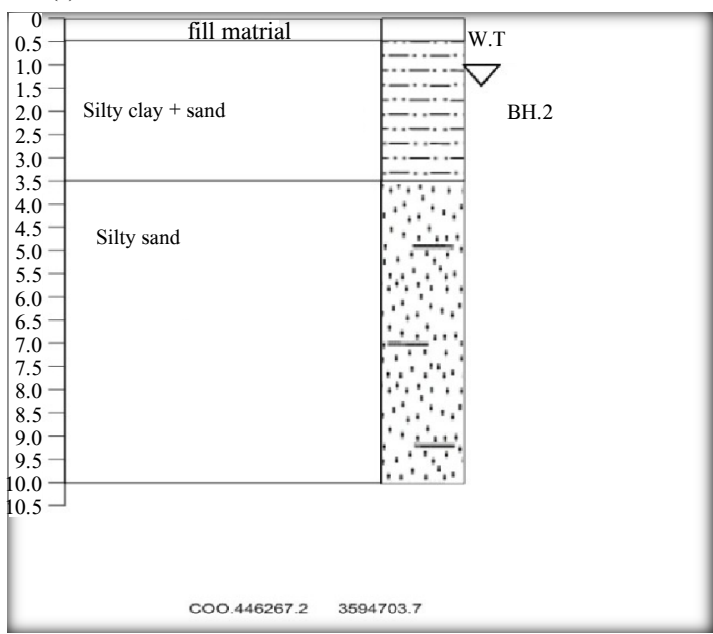

Fig. 2(a, b): Samples of boreholes in Hilla City

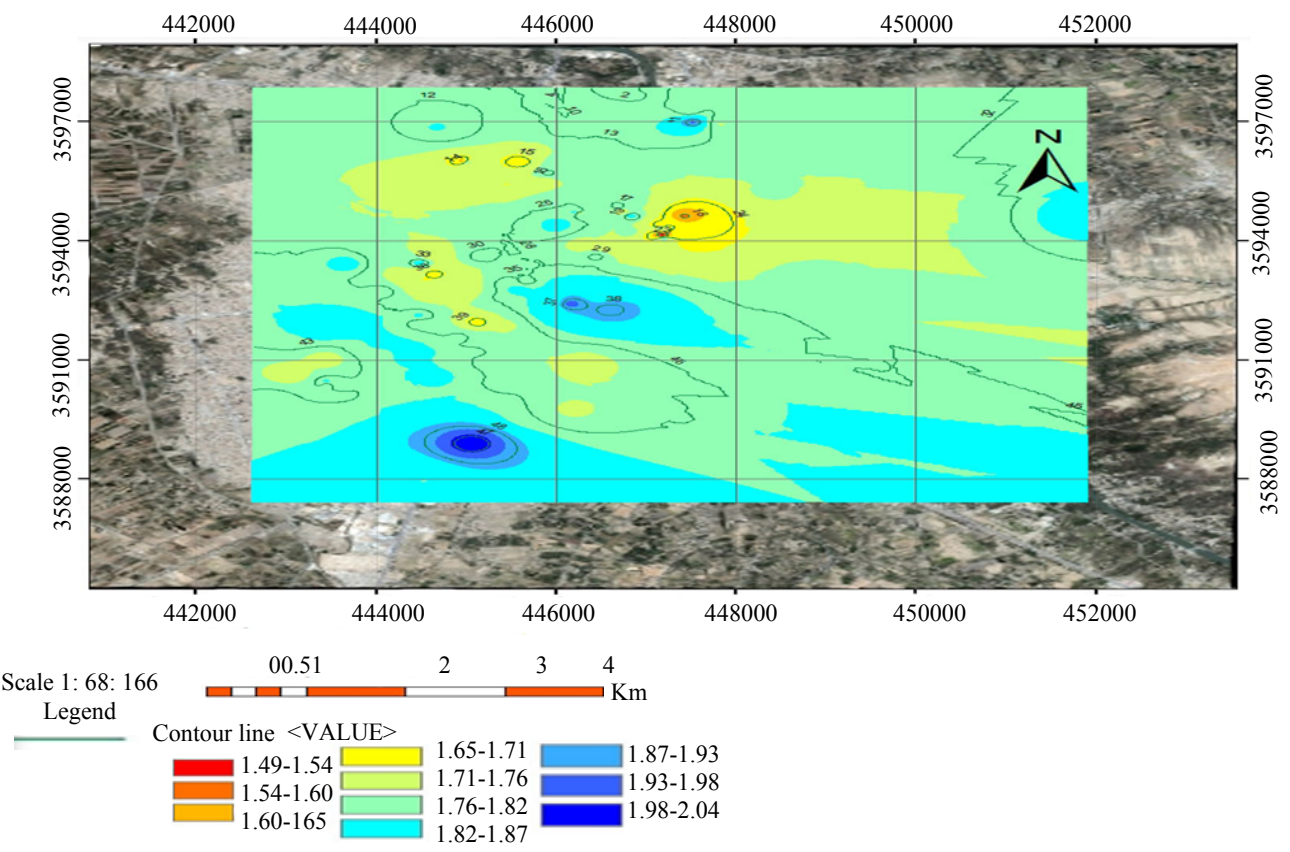

Fig. 3: The wet density values $\left(\mathrm{gcm}^{-3}\right)$ in the city of Hilla at a depth of $(1.5 \mathrm{~m})$

with ASTM D-1586 using standard penetration sampler to assess the relative density/consistency of the soils found and to maintain soil samples for laboratory testing. The penetration experiments were done by originally driving the sampler to the bottom of the borehole using a $63.5 \mathrm{~kg}$ hammer dropping freely from a height of $760 \mathrm{~mm}$ (Automatic Trip-Hammer Falling) with an internal diameter of $50 \mathrm{~mm}$ (Split spoon sampler). The sampler was pushed to penetrate soft soil cuttings the first $150 \mathrm{~mm}$ and the sampler was "seated". The sampler was then gradually driven an additional $300 \mathrm{~mm}$ with the results recorded as the corresponding number of blows required
"N" to advance the $300 \mathrm{~mm}$ sampler. In the field, soil samples obtained from the borings were packaged and sealed to reduce loss of moisture and disturbance and brought for testing to the laboratory. The value of SPT vary between 2-57 blow where the SPT values are observed with increasing depth to change the geotechnical characteristics of the soil by increasing depth and showing Fig. 6.

\section{Engineering properties}

Strength parameters: The strength of the soil is depicted by (undrained Cohesion $(\mathrm{Cu}$ ), (undrained angle of internal 
J. Eng. Applied Sci., 14 (Special Issue 8): 10389-10397, 2019

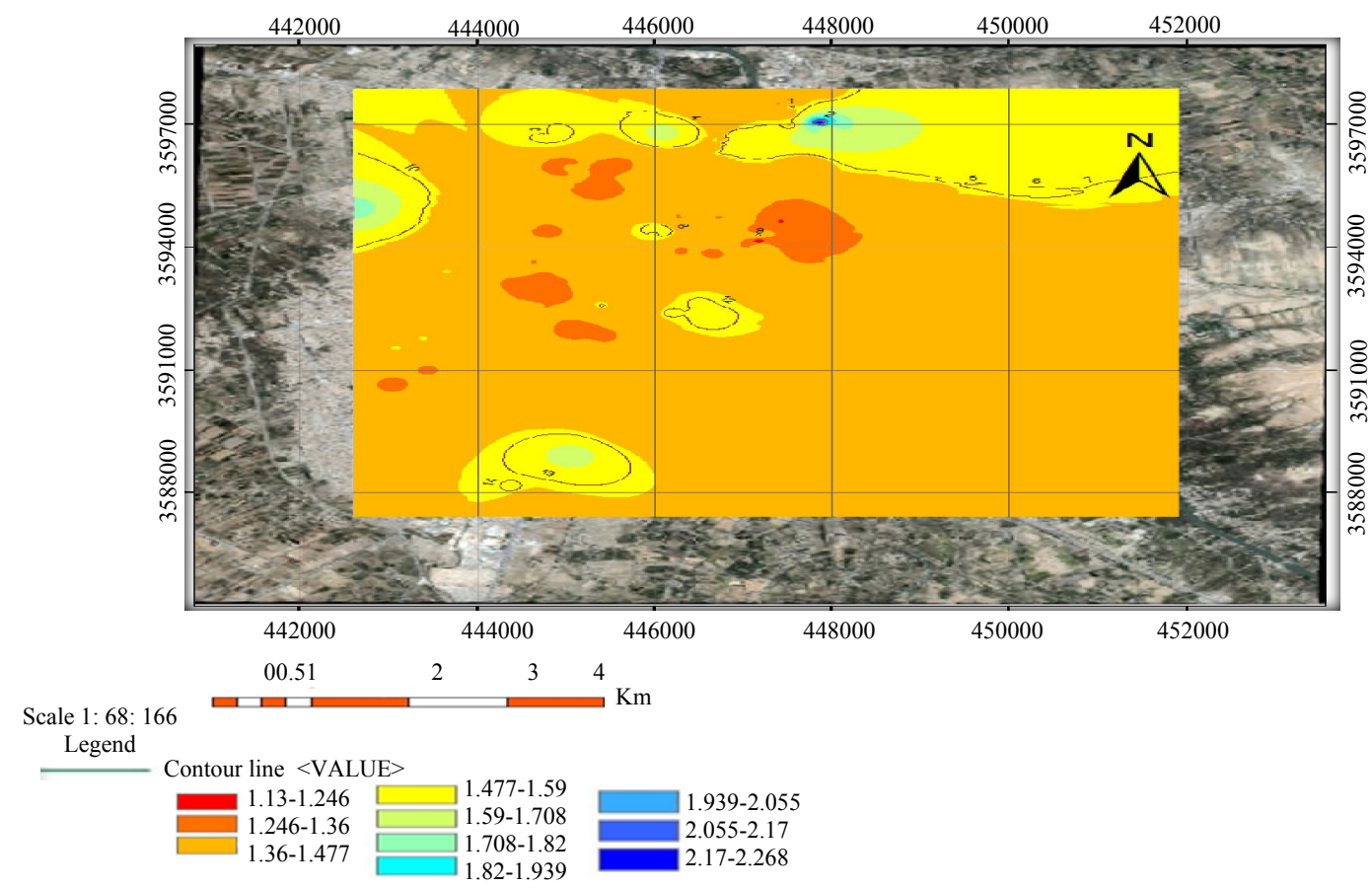

Fig. 4: The dry density values $\left(\mathrm{gcm}^{-3}\right)$ in the city of Hilla at a depth of $(1.5 \mathrm{~m})$

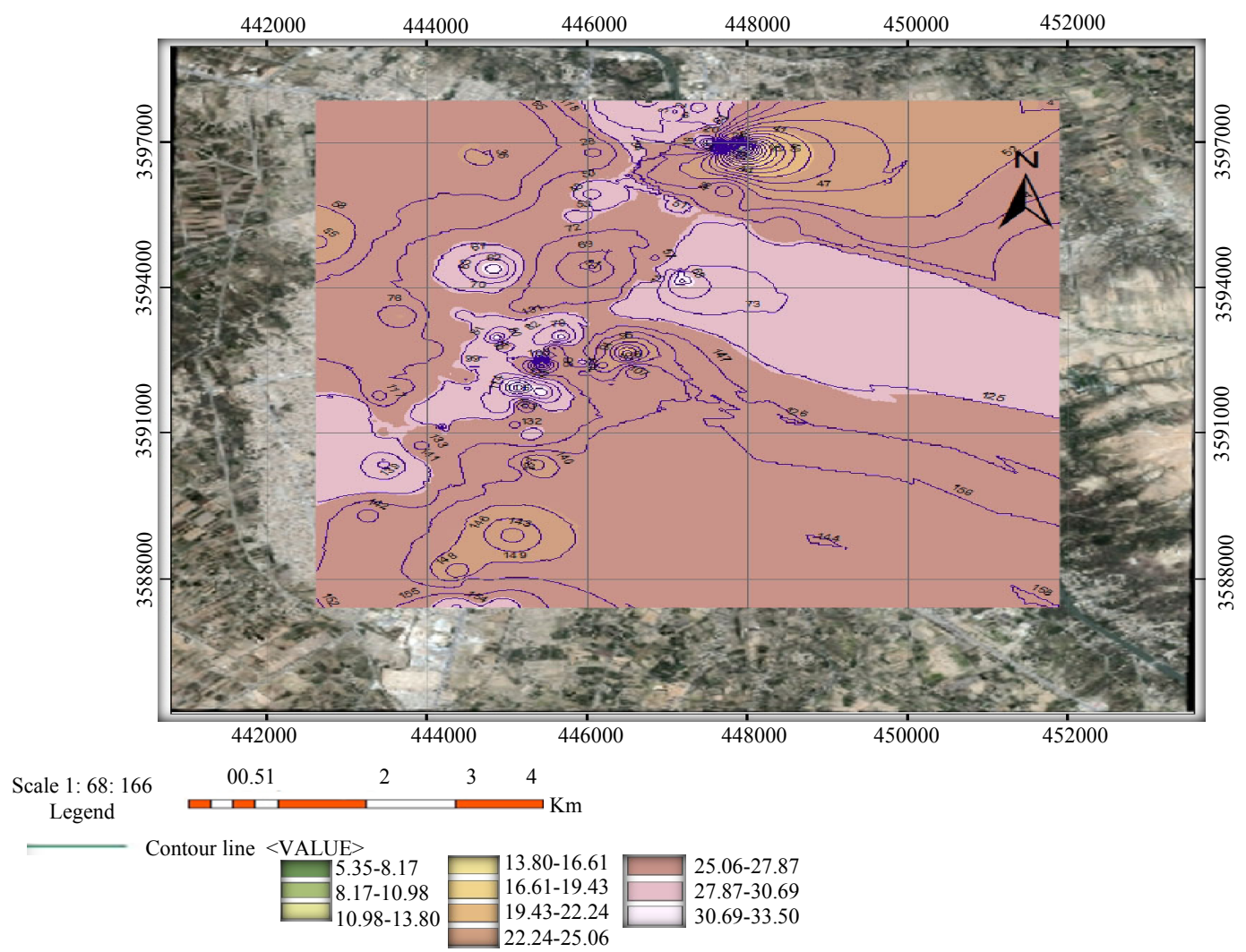

Fig. 5: Moisture content values in Al-Hilla city at depth (1.5 m)

friction ( $\varnothing u$ ), moist density ( $\rho w e t)$, dry density ( $\rho$ dry) and extreme ability of bearing (qu) (Smith, 1991). Tests of shear strength parameters for Al-Hilla city at depth from $0-10.5 \mathrm{~m}$. The results in cohesive values between 


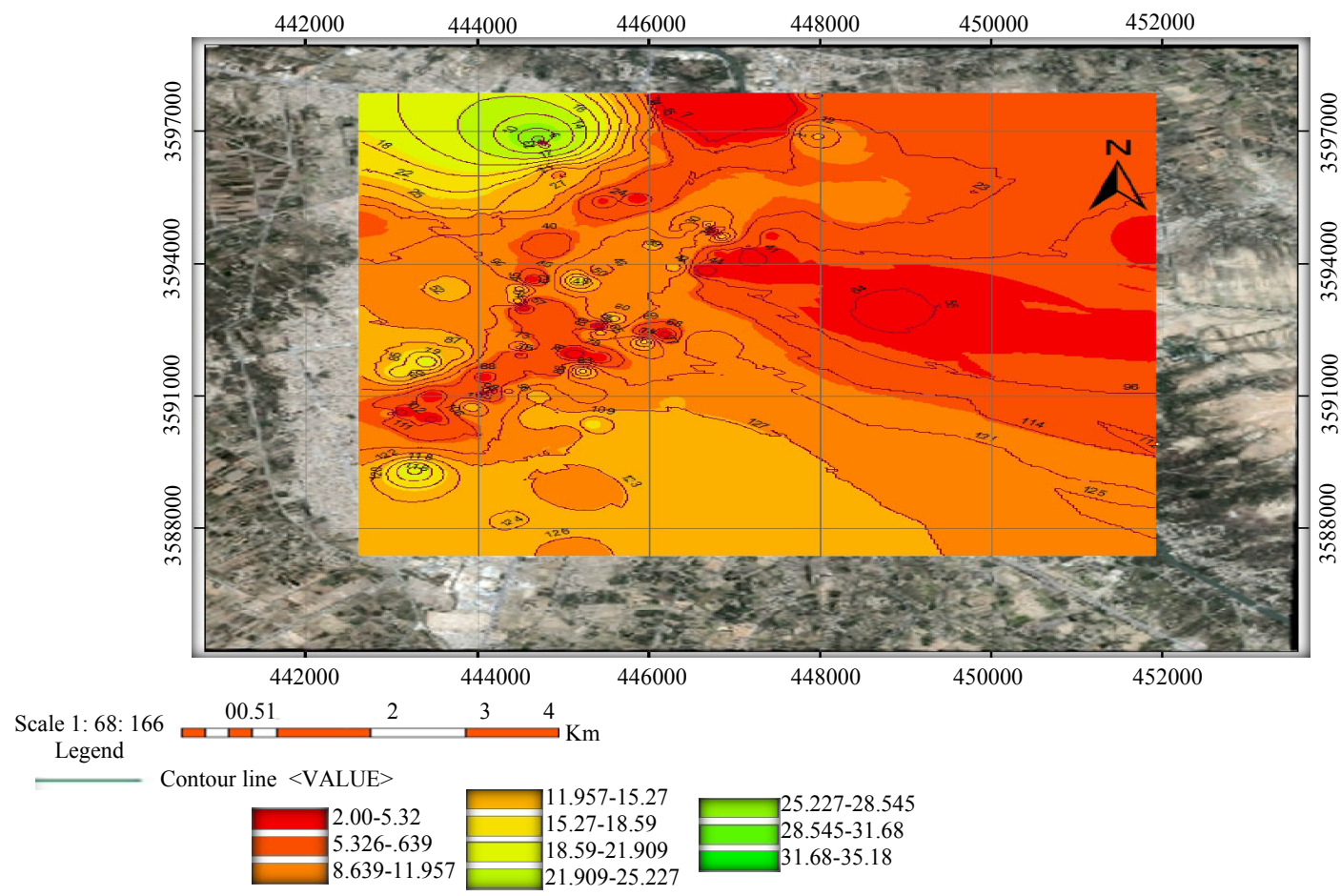

Fig. 6: The value of SPT in depth $1.5 \mathrm{~m}$
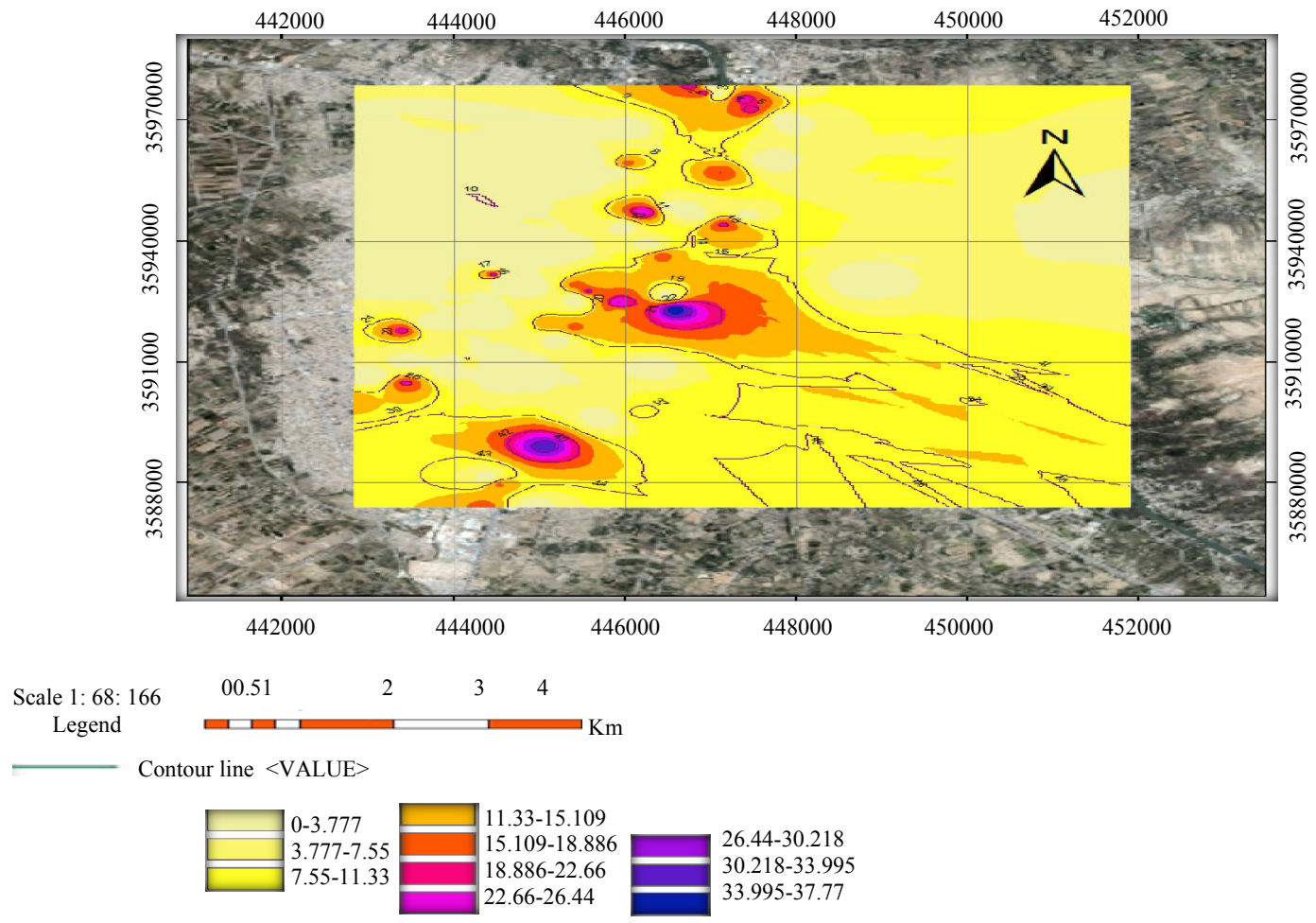

Fig. 7: The value of internal friction angle for depth $(1.5 \mathrm{~m})$ 
J. Eng. Applied Sci., 14 (Special Issue 8): 10389-10397, 2019
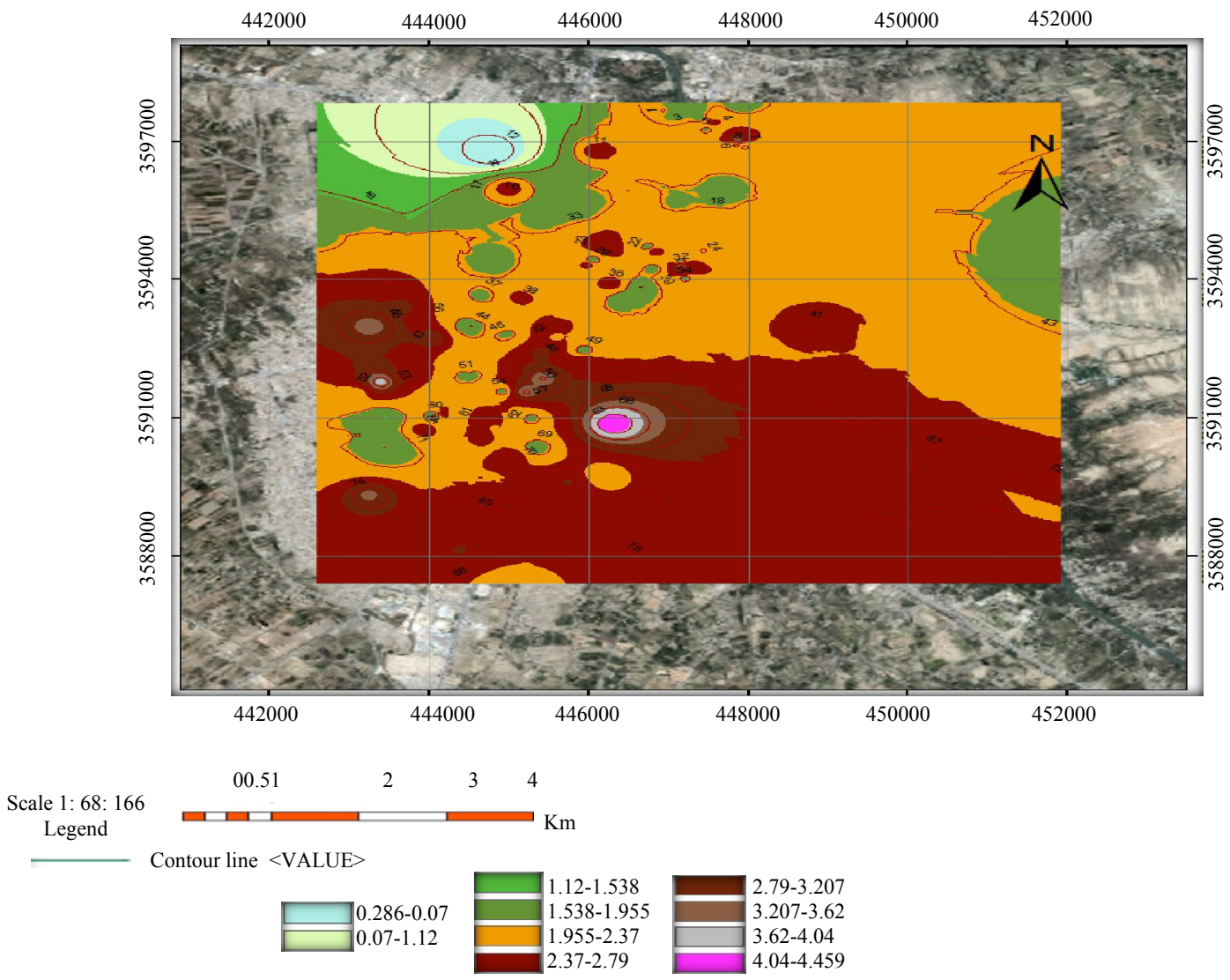

Fig. 8: The cohesive value for depth $(1.5 \mathrm{~m})$

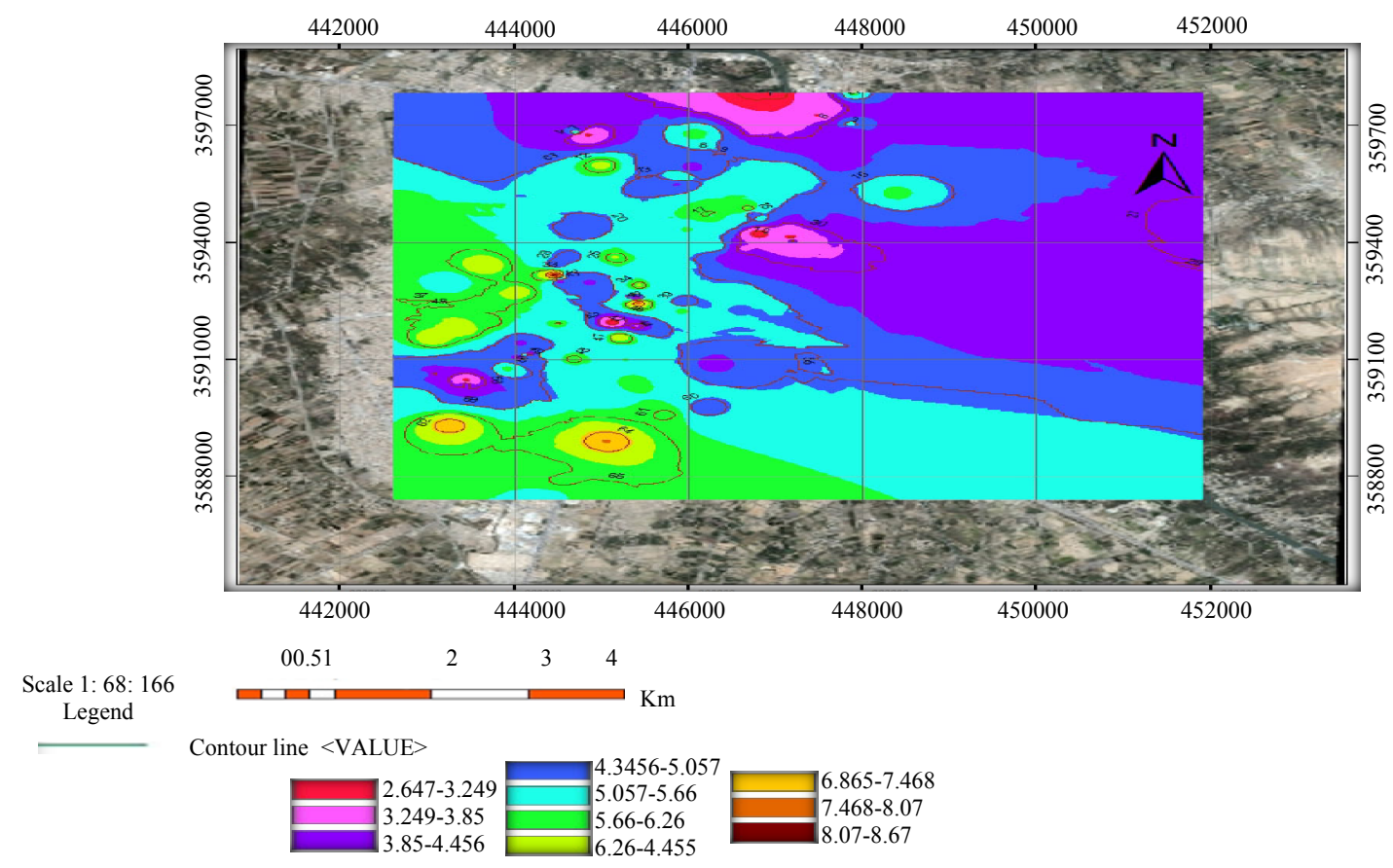

Fig. 9: Value bearing capacity at depth $(1 \mathrm{~m})$ 


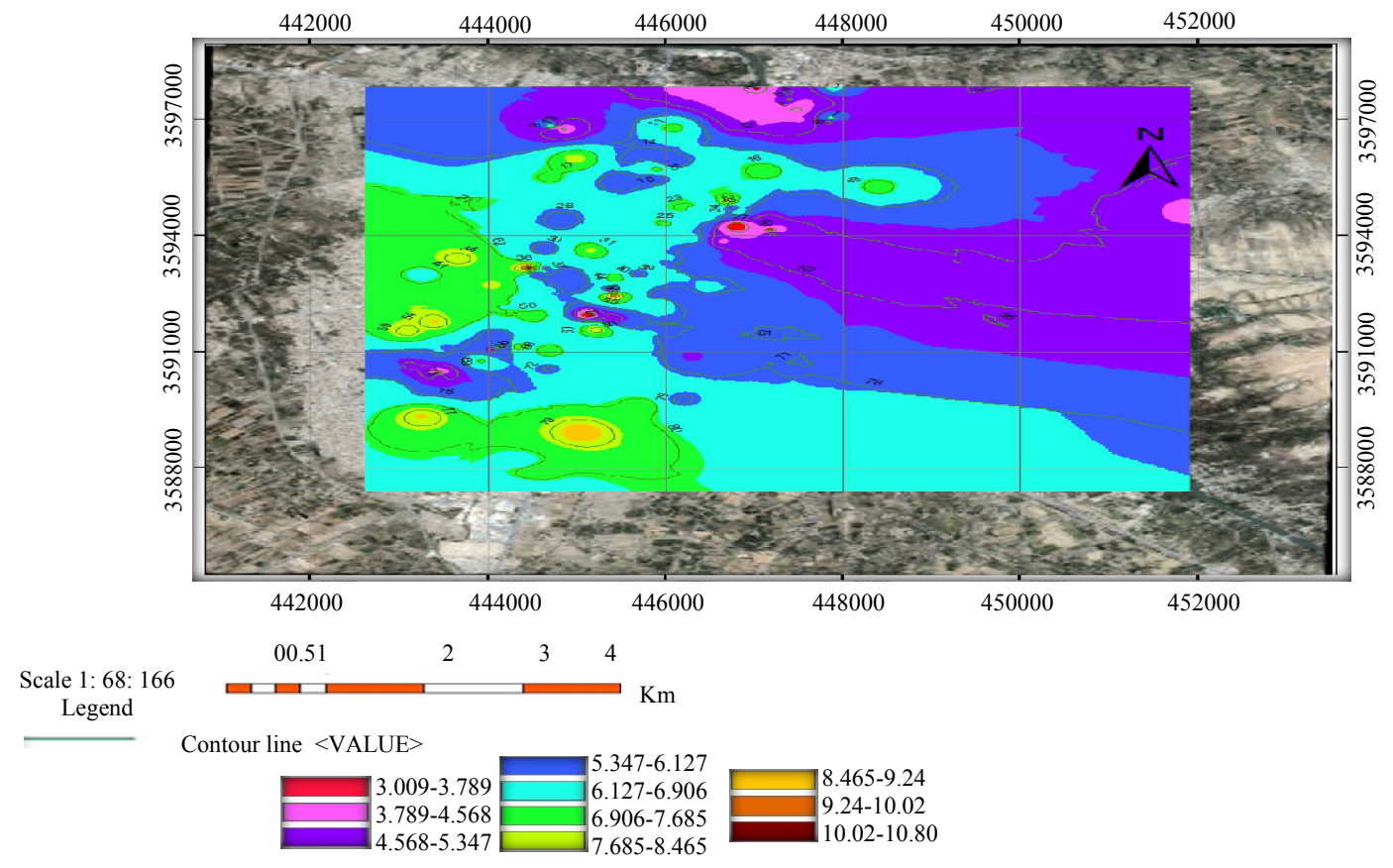

Fig. 10: Value bearing capacity at depth (2m)

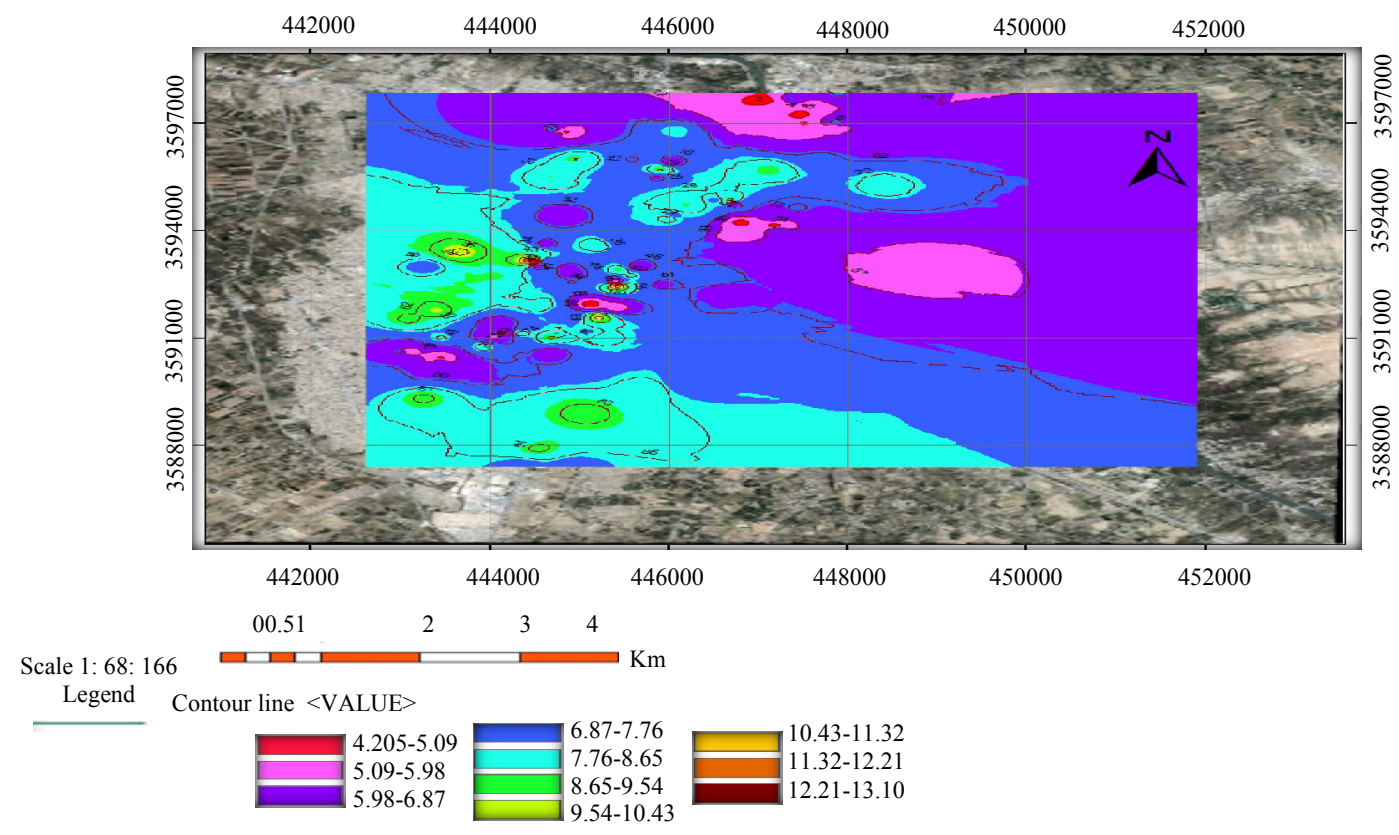

Fig. 11: Value bearing capacity at depth (3m)

0.25-5.77 $\mathrm{Tm}^{-2}$ and internal friction angle between $\left(0-43^{\circ}\right)$. Figure 7 and 8 show cohesive values and internal friction in Al-Hilla city. From this it can be concluded that the density of the sandy soil increases the friction angle while the shear resistance to the soil is high when the clay ratio is high in the soil, low the internal friction angle between the granules is small which in this case increases the resistance to cohesion.

Bearing capacity: Is defined as the amount of support strength shown by the soil where the term maximum bearing capacity is used to express the maximum 


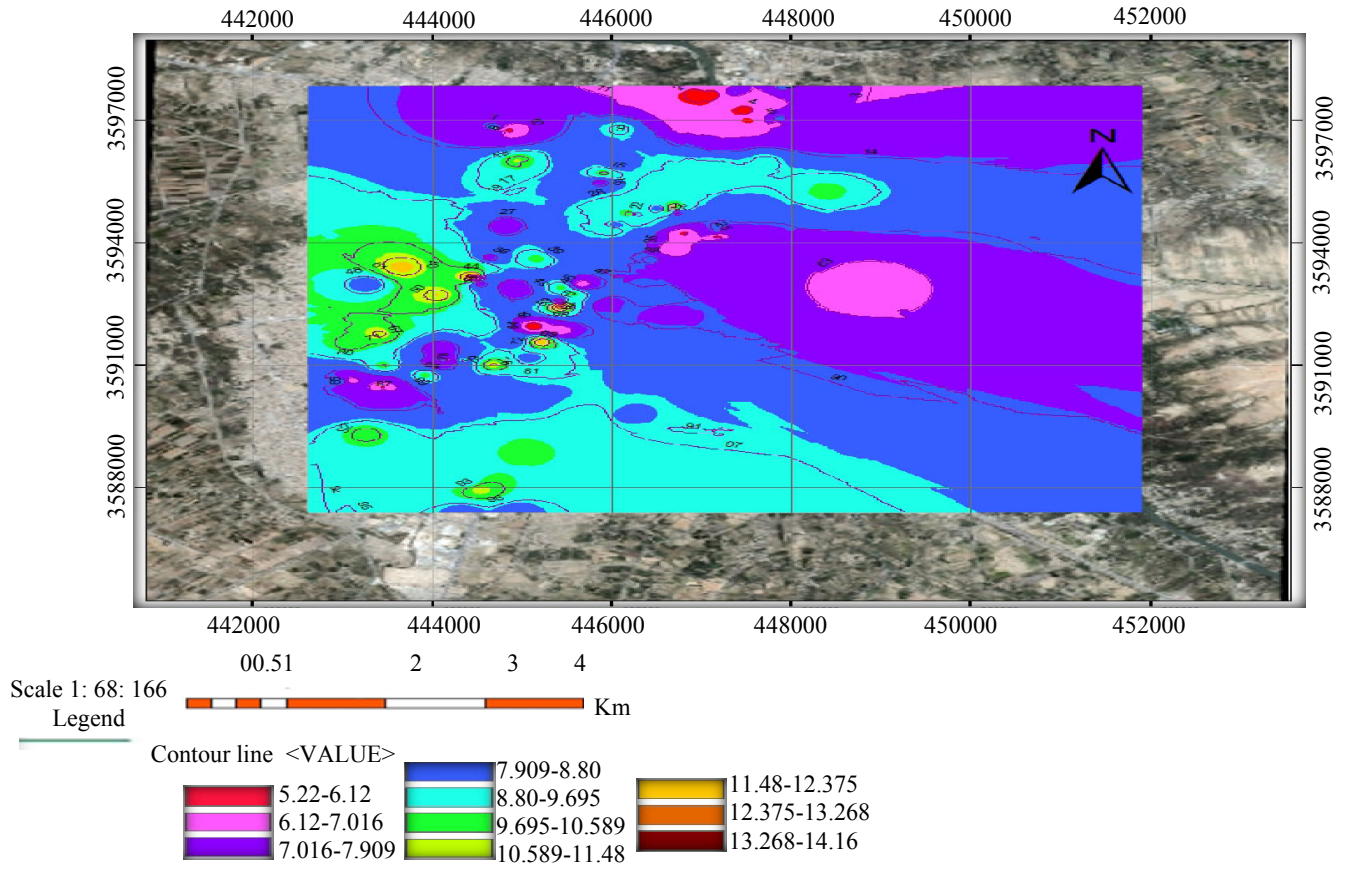

Fig. 12: Value bearing capacity at depth ( $4 \mathrm{~m})$

capacity to the soil towards the weights it holds. It is also known as the less dense density of the base and the failure occurs the shear strength (Terzaghi and Peck, 1967).

Represents geotechnical maps concerned with the carrying capacity of this research for Al-Hilla city at depths $(1.0-4.0 \mathrm{~m})$ are shown in Fig. 9-12. It was BC greatest value $\left(14.23 \mathrm{Tm}^{-2}\right)$ in location in 60 streetat depth $(4 \mathrm{~m})$. Minimum $\mathrm{BC}$ has been $\left(2.64 \mathrm{~T} / \mathrm{m}^{2}\right)$ in AL-Tessat depth $(1 \mathrm{~m})$.

\section{CONCLUSION}

The most important results are as follows: ArcGIS can provide a geotechnical map that contains a good visual display by the type and description of the database entered. The ability of GIS to provide overlapping data for more than one geotechnical property as a local guide can help to speak to the data and characteristics collected in an alternative probability that verifies the combined effect of properties.

Because the area is made up of the flood plains deposits of the Tigris and Euphrates rivers, we can observe the great fluctuation in the studied geotechnical properties which made it difficult to give these properties one form represented by increasing or decreasing with depth.

The soil of the province of Babylon is a layer of soil composed of layers of sand, silt and mud and organic matter of soil in residential areas in the province of Babylon has very few percentages except in some areas.
The atteerberg limit: the percentage PL is between $7.10-41 \%$, LL (11-64\%). These values are randomly distributed at different depths. The density of wet soil in Hilla ranged between $2.04-1.60 \mathrm{gcm}^{-3}$ and the dry density of soil in Hilla between 1.13-2.30 $\mathrm{gcm}^{-3}$. The values of Standard Penetration Test (SPT) were (2-57 blow).

The foundations of the facilities are designed depending on the capacity of soil bearing because it is considered the most important engineering characteristics. In general, the absorptive capacity of residential areas in Babil governorate increases with the depth and the Northern direction due to changes in soil layers, shallow depths, large changes in groundwater levels that occur in the capacity of endurance and due to the increase of natural land levels in the Northern direction.

\section{REFERENCES}

Al-Abody, A.A.M., 2016. Geotechnical maps of the soil of the province of Babylon using GIS. Master Thesis, University of Babylon, Hillah, Iraq.

Al-Baaj, G.A., 2017. GIS mapping of soil and ground water properties for Najaf and Kufa cities. M.Sc. Thesis, University of Babylon, Babil, Iraq.

Jumikis, A.R., 1962. Soil Mechanics. D. Van Nostrand Company, New York, USA.,.

Orhan, A. and H. Tosun, 2010. Visualization of geotechnical data by means of geographic information system: A case study in Eskisehir city (NW Turkey). Environ. Earth Sci., 61: 455-465. 
Smith, R., 1991. Element of Soil Mechanics in Civil Engineering. 6th Edn., Granada Publishing Ltd., London, UK.,.
Terzaghi, K., and R.B. Peck, 1967. Soil Mechanics in Engineering Practice. 2nd Edn., John Wiley \& Sons, New York, USA., Pages: 729. 